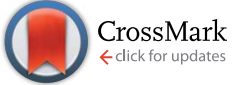

Cite this: Chem. Sci., 2017, 8, 1309

\section{Photochromic benzo[b]phosphole oxide with excellent thermal irreversibility and fatigue resistance in the thin film solid state via direct attachment of dithienyl units to the weakly aromatic heterocycle $\uparrow$}

\begin{abstract}
Nathan Man-Wai Wu, Hok-Lai Wong and Vivian Wing-Wah Yam*
A novel photochromic benzo[b]phosphole oxide has been demonstrated to display photochromic properties with excellent fatigue resistance and thermal irreversibility in polymethylmethacrylate (PMMA) thin film under ambient conditions. The remarkable photochromic behaviour can be achieved by rational molecular design, in which the weakly aromatic phosphole oxide is directly incorporated into the photoresponsive dithienylethene units. Photopatterning via photoinduced colouration and decolouration has been performed to demonstrate the repeatable and distinct transformation between the bistable states, making it a promising candidate with photoswitching properties for optoelectronic applications.
\end{abstract}

Received 4th July 2016

Accepted 30th September 2016

DOI: $10.1039 / \mathrm{c} 6 \mathrm{sc} 02928 \mathrm{k}$

www.rsc.org/chemicalscience
Among the photochromic compounds, ${ }^{5}$ diarylethenes have been regarded as one of the most attractive photochromic compounds given their promising thermal irreversibility, fatigue resistance and ability to carry out solid state photochromism. Various photochromic diarylethenes with different photo-controlled functions have been reported. ${ }^{5}$ However, most of the research has been confined to carrying out modifications of pendant aryl units attached to the perfluorocyclopentene backbone. ${ }^{3-6} \mathrm{~A}$ number of researchers have been expanding the structural diversity and functionality by incorporating diarylethene moieties into various heterocycles such as 1,10-phenanthroline, ${ }^{7}$ imidazole, ${ }^{8}$ thiophene, ${ }^{9}$ thiazole, ${ }^{10}$ benzo $[b]$ thiophen ${ }^{11}$ and thiophene-fused heteroacenes. ${ }^{12}$ However, a number of the aforementioned diarylethenes usually suffered from less than satisfactory practical thermal stability in the photogenerated closed form as well as a reduction in their robust fatigue resistance during photochromic cycles. Very recently, benzobisthiadiazole- ${ }^{13}$ and silole-fused ${ }^{14}$ diarylethenes that have satisfactory thermal stability and fatigue resistance have been reported. Isolation of pure photoactive anti-parallel conformers with an impressively high photocyclization quantum yield has been achieved for the sterically bulky benzobisthiadiazole-bridged diarylethenes. ${ }^{13 b}$ Besides, the highly efficient photo-switching capability arising from the high photocyclization and photocycloreversion quantum yields $\left(\phi_{\mathrm{O} \rightarrow \mathrm{C}} \approx\right.$ $0.48, \phi_{\mathrm{C} \rightarrow \mathrm{O}} \approx 0.42$ ), which led to effective writing and erasure processes that are rarely found in diarylethene systems, has been realized in the weakly aromatic silole-fused diarylethenes. ${ }^{14}$ Despite these exciting developments, there is still room for improvement and there is a need for research that will enable understanding for the rational design of heterocyclic- 
fused diarylethenes with promising photochromic behaviour, particularly those heterocycles that could be easily functionalized and derivatized.

Recently, phospholes have been extensively studied ${ }^{15-17}$ not only for their unique electronic structure and capability to finetune photophysical properties, ${ }^{\mathbf{1 6}}$ but also for their potential applications in optoelectronics. ${ }^{\mathbf{1 7}}$ It has now been widely accepted that phosphole possesses less aromatic character due to the fact that the lone pair of electrons of phosphorus cannot be effectively delocalized into the $\pi$-system of the butadiene moiety, with the slight aromaticity of phosphole resulting from hyperconjugation between the endocyclic $\pi$-system and the exocyclic $\sigma$-bond. ${ }^{15}$ With our continuous interest in designing various photochromic materials, ${ }^{7-9,12,14,18}$ we envisioned that the direct attachment of two thienyl rings onto the phosphole ring would offer a strategy to optimize the photochromic performance of the system. Although phosphole-containing photochromic compounds have been reported previously, ${ }^{18}$ the photochromic bis-thienyl units are not directly attached onto the ethene unit of the phosphole ring to take advantage of the low aromaticity of phosphole, and to the best of our knowledge, exploration of the direct attachment of the two thienyl units to the phosphole ring has never been reported. In addition, studies on the photochromic properties of thin films of fusedheterocycle diarylethenes under ambient conditions are still not as extensively explored as those of the perfluorocyclopentene analogues. It is envisaged that the demonstration of thin film photochromism with excellent thermal irreversibility and with the fatigue resistance of fused-heterocycle diarylethenes could offer alternative promising candidates for future potential applications in photoswitching and optical memory devices. Herein, we report the synthesis and characterization, as well as the photophysical and photochromic properties of novel photochromic benzo[b]phosphole derivatives 1-8 (Fig. 1), in which benzo[ $b]$ phosphole oxide $\mathbf{1}$ has been employed to illustrate the capabilities of this class of compounds in performing solution, crystalline and thin film photochromism with excellent thermal irreversibility and fatigue resistance. More importantly, this molecular design strategy involving the direct attachment of the bis-dimethylthienyl moieties to the weakly aromatic phosphole unit has been proven to greatly enhance the photochromic performance, in areas such as thermal

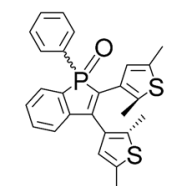

1

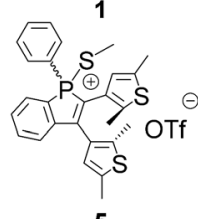

5

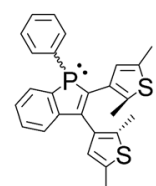

2

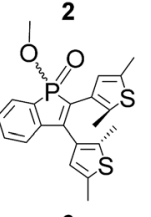

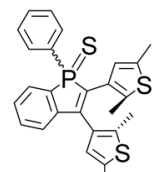

3

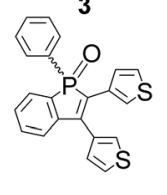

7

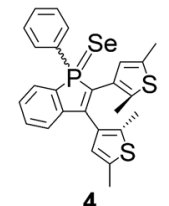

4

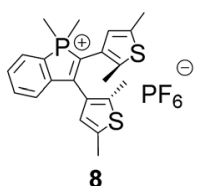

8
Fig. 1 Chemical structure of the photochromic benzo[b]phosphole derivatives $1-8$. irreversibility and fatigue resistance, as well as the photocyclization and photocycloreversion quantum yields in comparison to previously reported fused-heterocycle diarylethenes. ${ }^{-9, \mathbf{9 2 , 1 8}}$ The present work provides important insights and guiding principles into the molecular design of photochromic diarylethene systems with excellent thermal irreversibility and fatigue resistance.

\section{Results and discussion}

\section{Synthesis, characterization, electrochemical and photophysical studies}

Photochromic benzo[b]phosphole oxides 1, 6 and 7 were prepared by silver-mediated dehydrogenative annulation of phenyl hydrophosphine oxides and diarylacetylenes, ${ }^{\mathbf{1 9} \boldsymbol{a}-\boldsymbol{b}}$ whereas the photochromic benzo[b]phosphole derivatives 2-5 and 8 were prepared by functionalization of the phosphorus centre, using a modified version of a literature procedure for the synthesis of phosphole derivatives. ${ }^{19 c-f}$ The synthetic routes are summarized in Scheme S1 in the (ESI $\dagger$ ). 1-8 have been characterized by ${ }^{1} \mathrm{H}$ and ${ }^{31} \mathrm{P}\left\{{ }^{1} \mathrm{H}\right\}$ NMR spectroscopy, as well as EI-HRMS and elemental analysis. Two sets of ${ }^{1} \mathrm{H}$ and ${ }^{31} \mathrm{P}\left\{{ }^{1} \mathrm{H}\right\}$ NMR signals are found for 1-6 at room temperature, resulting from the presence of diastereomeric mixtures arising from the existence of $R$ and $S$ forms and the chiral $P$ and $M$ helices. ${ }^{6,13 c} 7$ and 8, which lack a chiral centre and chiral helix, are found to have only one set of ${ }^{1} \mathrm{H}$ and ${ }^{31} \mathrm{P}\left\{{ }^{1} \mathrm{H}\right\}$ NMR signals, further establishing the diastereomeric relationship of the two sets of NMR signals. The representative benzo[b]phosphole oxide 1 has also been structurally determined by X-ray crystallographic analysis and its perspective view is shown in Fig. 2. The diastereomer of $\mathbf{1}$ which has a $P$ chiral helix and $R$ chiral centre has been obtained in the crystal structure. Moreover, it has been found to adopt an antiparallel conformation in the crystalline solid state, in which the distance between the two photoreactive carbon atoms is estimated to be within $3.60 \AA$, indicating that 1 may exhibit crystalline solid state photochromism in a restricted spatial environment. ${ }^{5,5 g}$

1-6 showed irreversible oxidation waves ranging from +1.34 to $+1.72 \mathrm{~V} v s$. SCE (Table S1 $\dagger$ ). The first oxidation of 1-6 is tentatively assigned as the oxidation of the dimethylthienyl moieties, with a mixing of the phosphole-centred oxidation due to the rather low sensitivity towards the $P$-substituents and the

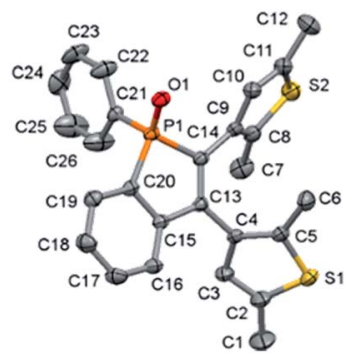

Fig. 2 Perspective view of benzo[b]phosphole oxide 1 with atomic numbering. Hydrogen atoms have been omitted for clarity. Thermal ellipsoids were shown at the $30 \%$ probability level. 
presence of electron-rich peripheral dimethylthienyl moieties. ${ }^{18}$ Moreover, 1-6 showed reduction waves ranging from -0.91 to $-1.99 \mathrm{~V} v s$. SCE (Table $\mathrm{S} 1 \dagger$ ). The first reduction is tentatively assigned as the phosphole-centred reduction because of the strong dependence of the different substituents on the phosphole moiety. ${ }^{18}$ The electronic absorption spectra of 1-8 in benzene show moderately intense absorption bands at about 300-480 nm (Table 1 and Fig. S1 $\dagger$ ), which are tentatively assigned as intraligand $\pi-\pi^{*}$ transitions with a possible involvement of intramolecular charge transfer transitions from the peripheral dimethylthienyl moieties to the central benzo[ $b]$ phosphole unit. ${ }^{18}$ Upon excitation into the absorption band at about $320-400 \mathrm{~nm}$ of 1-8 in degassed benzene solution, the benzo $[b]$ phosphole derivatives with the exception of 3 and 4 display blue and yellow luminescence at about $430-530 \mathrm{~nm}$ (Table 1 and Fig. S2†). The emission maximum of the representative compound $\mathbf{1}$ shows a strong solvent dependence, with a linear relationship between the emission energy and Dimroth's $E$ solvent parameter, ${ }^{20}$ as shown in Fig. S3 and S4, $\dagger$ suggesting the involvement of a charge transfer character in the transition.

\section{Photochromic studies}

The degassed benzene solutions of the open forms of the photochromic benzo[ $b]$ phosphole derivatives are found to exhibit colour changes from colourless and pale yellow solutions to deep reddish-orange, pale purple and reddish-purple (Fig. 3), respectively, upon UV excitation at around $360 \mathrm{~nm}$. The appearance of a low-energy absorption band at about 450$600 \mathrm{~nm}$ is indicative of the occurrence of a photocyclization reaction and formation of the closed forms, as depicted in Fig. 4 and $\mathbf{S} 5-\mathrm{S} 11, \dagger$ with the colour derived from the extended $\pi$-conjugation on the 1,8-thia-as-indacene moiety (Fig. 3). In
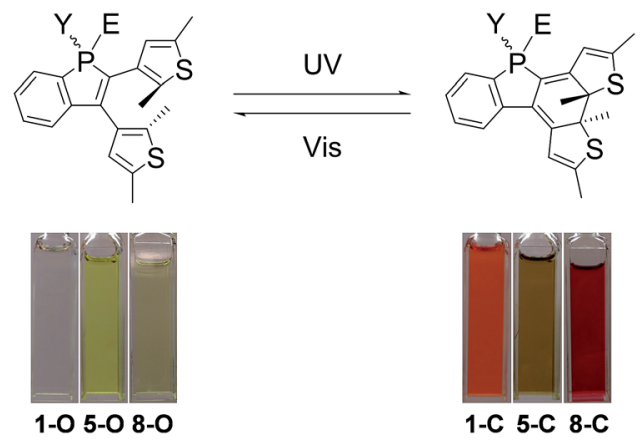

Fig. 3 Photochromic reactions and colour changes of 1, 5 and 8 in degassed benzene solution upon light excitation at $298 \mathrm{~K}$.

addition, both sets of ${ }^{1} \mathrm{H}$ NMR signals are found to diminish with concomitant growth of two new sets of signals, which originate from the closed form isomers. The constant relative ratio of the two sets of signals of the open form during the photochemical process further supports the assignment of the diastereomeric relationship instead of distinct parallel and antiparallel conformers. By photoirradiation into the newly formed low-energy absorption bands at around $500-600 \mathrm{~nm}$ in the degassed benzene solutions, the closed form isomers undergo a photocycloreversion reaction, as indicated by a reversal of the UV-visible spectral changes.

The tunability of the photochromic benzo $[b]$ phosphole system is demonstrated by systematic variations of the $P$-substituents. The characteristic lowest-energy absorption bands of the closed forms vary from about $450 \mathrm{~nm}$ to $575 \mathrm{~nm}$ (Table 1 and Fig. S12 $\dagger$ ). The absorption energies of the closed forms are found to be rather insensitive to the various $P$-substituents [1-4 (500 nm)] but highly perturbed by the presence of the strong electron-accepting phosphorus centre $[\mathbf{1}(500 \mathrm{~nm})>\mathbf{8}(530 \mathrm{~nm}) \approx \mathbf{5}(550 \mathrm{~nm})]$ as well as

Table 1 Photophysical data of $1-8$

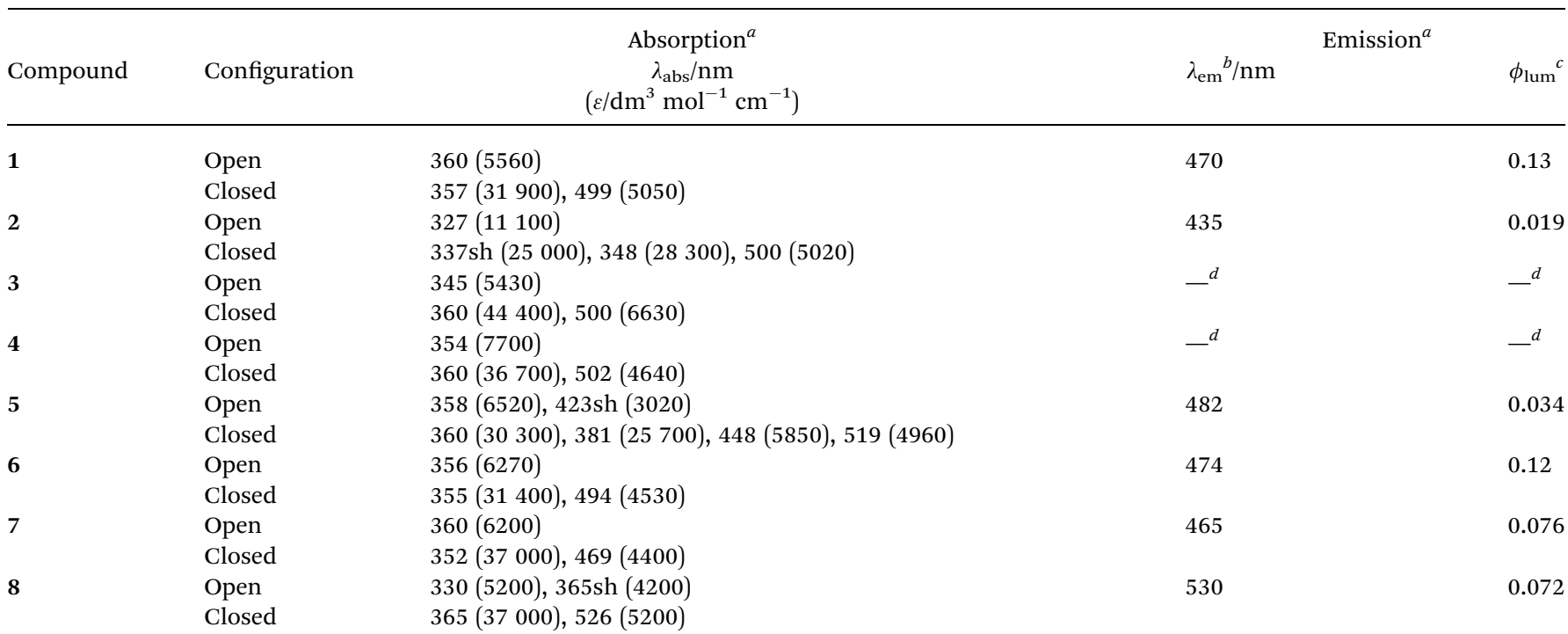

${ }^{a}$ Data obtained in degassed benzene solution at $298 \mathrm{~K} .{ }^{b}$ Emission maxima are corrected values. ${ }^{c}$ The relative luminescence quantum yields are reported using quinine sulphate in $0.5 \mathrm{M}$ sulfuric acid as standard at $298 \mathrm{~K} .{ }^{d}$ Non-emissive. 


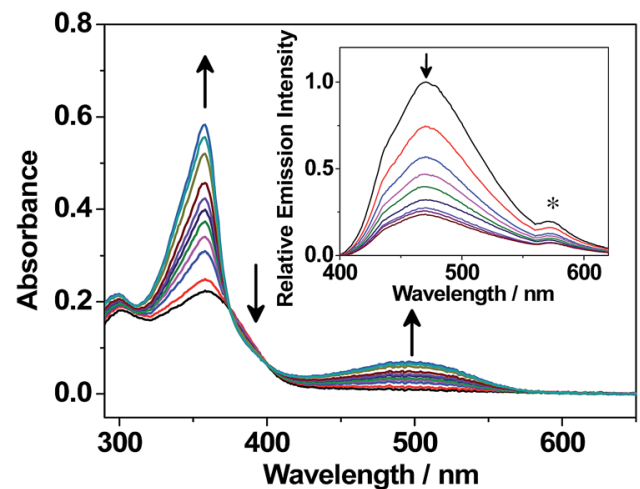

Fig. 4 UV-vis absorption spectral changes of benzo[b]phosphole oxide 1 in degassed benzene solution upon UV excitation at $360 \mathrm{~nm}$. The inset shows the plot of emission spectral changes upon excitation at $375 \mathrm{~nm}$; the asterisk represents an instrumental artifact.

electron-donating substituents on the peripheral dithienyl group [7 $(470 \mathrm{~nm})>1(500 \mathrm{~nm})]$. Apart from the UV-vis absorption spectral changes, emission spectral changes are also observed during the photochromic reaction. Upon UV excitation, the emission intensity of the degassed benzene solution of $\mathbf{1}$ decreases gradually at around $470 \mathrm{~nm}$ (Fig. 4).

Interestingly, the photochromic quantum yields of this series of benzo[ $b]$ phosphole derivatives 1-8 (Table 2) are found to be higher than those of other fused-heterocycle diarylethenes..$^{-9,12,18}$ For 1, the photocyclization and photocycloreversion quantum yields are found to be 0.64 and 0.24 , respectively, in which the photocyclization/photocycloreversion quantum yields are both higher than most of the fusedheterocycle diarylethenes $\left(\phi_{\mathrm{O} \rightarrow \mathrm{C}}<0.50, \phi_{\mathrm{C} \rightarrow \mathrm{O}}<0.10\right)$ reported in the literature..$^{-9,12,18}$ It is anticipated that the high quantum yields of this new series of photochromic derivatives would give rise to more efficient bi-directional photoresponses, providing a potential for future applications as photo-memories and photoswitchable devices. ${ }^{2-3}$ On the other hand, the photochromism of $\mathbf{1}$ has been found to benefit from the direct incorporation of a diarylethene moiety into the weakly aromatic phosphole, displaying robust fatigue resistance and excellent thermal irreversibility over other fused-heterocycle diarylethenes. ${ }^{7-12,18}$ The degassed benzene solution of $\mathbf{1}$ shows no severe decomposition $(<5 \%)$ over seven photochromic cycles, in which the closed form is almost completely converted back to the open form (Fig. S13†). Compound 2 also shows excellent fatigue resistance, similar to that of $\mathbf{1}$ (Fig. S14 $\dagger$ ). The thermal stability of the closed form of $\mathbf{1}$ in a degassed 1,2-dichlorobenzene solution has been investigated at room temperature and at $100{ }^{\circ} \mathrm{C}$. The thermally induced backward reaction is found to be negligible $(<1 \%)$ even at $100{ }^{\circ} \mathrm{C}$ for 2000 minutes. The thermal decay rate constant and the half-life are estimated to be $2.76 \times$ $10^{-6} \mathrm{~min}^{-1}$ and 174 days at $100^{\circ} \mathrm{C}$, respectively (Fig. S15†). The thermal stability of the closed form of $\mathbf{1}$ is comparable to that of diarylperfluorocyclopentenes ${ }^{5 a, 5 g}$ and superior to other fusedheterocycle diarylethenes. ${ }^{7-12,18}$ The property of thermal irreversibility is governed by the ground state energy difference between the open form and the closed form isomers. ${ }^{5 a}$ Excellent thermal irreversibility of the photochromic systems can be achieved by direct attachment of the dithienyl unit to heterocyclic backbones that show less aromatic character and hence lower aromatic stabilization energy, so as to minimize the ground state energy difference between the open form and the closed form isomers. This class of benzo[b]phosphole derivatives reported herein represents one of the promising candidates that may have potential applications in the development of photoswitchable functional devices due to its low aromaticity and ease of functionalization.

Considering the excellent thermal irreversibility, robust fatigue resistance and rather efficient photochromic quantum yields of $\mathbf{1}$ in the solution state, solid state crystalline photochromism has also been demonstrated (Fig. 5a). The colourless crystal of 1 turns red in colour upon UV excitation, and then the red crystal returns to colourless upon photo-irradiation of visible white light. In view of the efficient and reversible crystalline photochromism, $\mathbf{1}$ has been doped into PMMA and spincoated onto a quartz plate to study the thin film solid state photochromism (Fig. 5b and c). Upon UV excitation, the UV-vis spectral changes of $\mathbf{1}$ on the PMMA thin film are very similar to that in the degassed benzene solution (Fig. S16†), with two isosbestic points, indicating a clean transformation between

Table 2 Photochromic data of 1-8

\begin{tabular}{llll}
\hline & \multicolumn{2}{c}{${\text { Photochemical quantum yield } / \phi^{a}}^{2}$} & \\
\cline { 2 - 3 } Compound & Photocyclization $^{b, c}$ & Photocycloreversion $^{b, d}$ & Conversion at photostationary state (PSS) $^{a, e}(\%)$ \\
\hline $\mathbf{1}$ & 0.64 & 0.24 & 34 \\
$\mathbf{2}$ & 0.73 & 0.20 & 71 \\
$\mathbf{3}$ & 0.52 & 0.15 & 62 \\
$\mathbf{4}$ & 0.65 & 0.29 & 59 \\
$\mathbf{5}$ & 0.20 & 0.074 & 54 \\
$\mathbf{6}$ & 0.39 & 0.093 & 20 \\
$\mathbf{8}$ & 0.092 & 0.27 & 59
\end{tabular}

${ }^{a}$ Data obtained in degassed benzene solution at $298 \mathrm{~K}$, with an uncertainty of $\pm 10 \%$. ${ }^{b}$ Data obtained using ferrioxalate as the chemical actinometer. ${ }^{c}$ Data obtained using $334 \mathrm{~nm}$ as the excitation wavelength. ${ }^{d}$ Data obtained using $500 \mathrm{~nm}$ as the excitation wavelength. ${ }^{e}$ Data obtained using $360 \mathrm{~nm}$ as the excitation wavelength. 
(a)

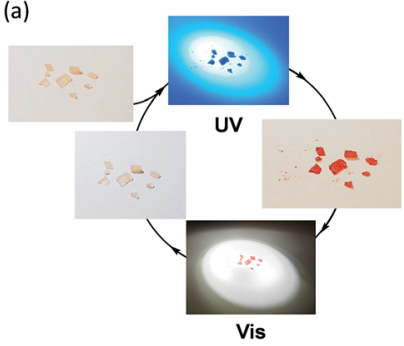

(c)

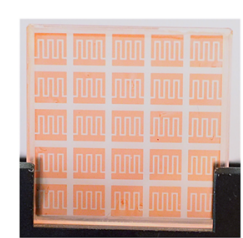

(b)

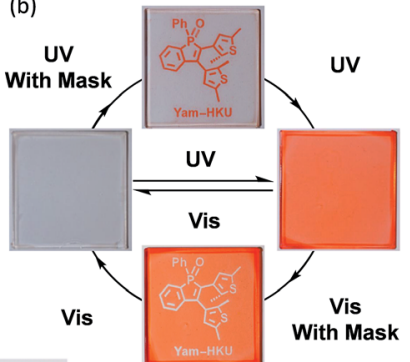

Fig. 5 (a) Crystalline and (b-c) PMMA thin film photochromism of 1.

the open and closed form isomers both in the PMMA thin film and in the degassed benzene solution. The fatigue resistant properties of 1 on the PMMA thin film have been studied under ambient conditions. It showed a comparable fatigue resistance on the PMMA thin film to that in the degassed benzene solution. No apparent loss of the photochromic reactivity is observed and the photogenerated closed form isomer is able to convert back to the open form completely with seven photochromic cycles (Fig. 6a). The closed form isomer of 1 shows excellent thermal stability on the PMMA thin film at room

(a)

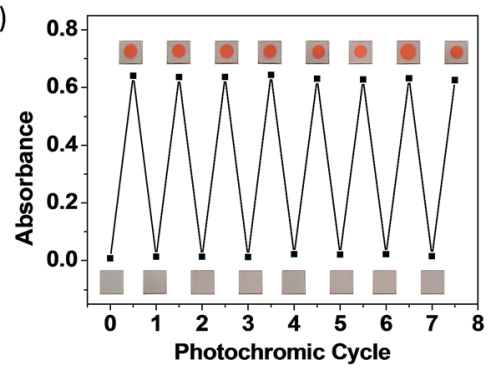

(b)

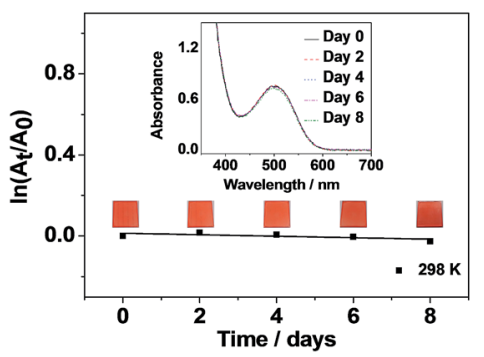

Fig. 6 (a) UV-vis absorbance changes at $500 \mathrm{~nm}$ of 1 upon alternate excitations at $360 \mathrm{~nm}$ and $500 \mathrm{~nm}$ over seven cycles on the PMMA thin film at $298 \mathrm{~K}$. The inset shows the colour change of the PMMA thin film during the photochromic reaction. (b) A plot of $\ln \left(A_{t} / A_{0}\right)$ versus time for the absorbance decay at $500 \mathrm{~nm}$ of the closed form isomer of 1 on the PMMA thin film under ambient and dark conditions over a week. $A_{0}$ and $A_{t}$ denote initial absorbance and absorbance at time $t$, respectively; the solid lines represent theoretical linear fits. The inset shows the electronic absorption spectra of each measurement during the 2-day time interval. temperature under ambient and dark conditions. No obvious thermal decay $(<3 \%)$ of the closed form to the open form isomer is observed over a week (Fig. 6b). It is interesting to note that while 1 shows a slight drop in fatigue resistance over seven photochromic cycles in oxygenated benzene solution (Fig. S17†), the thin films of 1 under non-degassed ambient conditions show excellent fatigue resistance with no obvious loss of photochromic reactivity, which is highly attractive for possible practical applications. Furthermore, the sharp contrast of the bistable states that are coloured (ON) and colourless (OFF) have been illustrated by photopatterning via photoinduced colouration and decolouration (Fig. 5b and c). Typically, the complete photo-modulated transformation between the ON and OFF states would render an unambiguous photo-controlled state of the systems.

\section{Conclusions}

To conclude, a series of newly designed photochromic benzo[ $b]$ phosphole derivatives has been shown to display remarkable photochromic properties including thermal irreversibility and fatigue resistance, as well as high photochromic ring-closing/ opening quantum yields when compared to the previously reported photochromic diarylethene-containing heterocycles ${ }^{7-12,18}$ by utilizing the direct attachment of the dithienyl unit to the weakly aromatic phosphole backbone. With the excellent photochromic properties of this benzo[b]phosphole oxide $\mathbf{1}$ in solution, crystalline and thin film solid states, it is believed that this work can provide a deeper insight into the rational design of photochromic materials for potential applications in the future. Further development of the photochromic phospholes with various structural modifications, investigation of the structure-activity relationship as well as the incorporation of additional functional moieties to achieve multifunctional photo-responsive materials are now in progress.

\section{Acknowledgements}

V. W.-W. Y. acknowledges support from The University of Hong Kong under the URC Strategic Research Theme on New Materials. This work was supported by the ANR/RGC joint Research Scheme (A-HKU704/12), the Research Grants Council (RGC) General Research Fund (GRF) (HKU 17305614) and the University Grants Committee (UGC) Areas of Excellence Scheme (AoE/P-03/08). N. M.-W. W. acknowledges the receipt of a postgraduate studentship from The University of Hong Kong. We are grateful to Ms H.-S. Chan at The Chinese University of Hong Kong for the assistance in X-ray crystal structure data collection and determination as well as Dr C.-T. Poon and Dr Eugene Y.-H. Hong for their discussions on this project.

\section{Notes and references}

1 S. R. Forrest, Nature, 2004, 428, 911-918.

2 (a) M.-M. Russew and S. Hecht, Adv. Mater., 2010, 24, 33483360; (b) E. Orgiu and P. Samorì, Adv. Mater., 2014, 26, 18271845; (c) C. Jia, A. Milgliore, N. Xin, S. Huang, J. Wang, 
Q. Yang, S. Wang, H. Chen, D. Wang, B. Feng, Z. Liu, G. Zhang, D.-H. Qu, H. Tian, M. A. Ratner, H. Q. Xu, A. Nitzan and X. Guo, Science, 2016, 352, 1443-1445.

3 (a) P. Zacharias, M. C. Gather, A. Köhnen, N. Rehmann and K. Meerholz, Angew. Chem., Int. Ed., 2009, 48, 4038-4041; (b) E. Orgiu, N. Crivillers, M. Herder, L. Grubert, M. Pätzel, J. Frisch, E. Pavlica, D. T. Duong, G. Bratina, A. Salleo, N. Koch, S. Hecht and P. Samorì, Nat. Chem., 2012, 4, 675679; (c) R. C. Shallcross, P. Zacharias, A. Köhnen, P. O. Körner, E. Maibach and K. Meerholz, Adv. Mater., 2013, 25, 469-476; (d) R. Shallcross, P. O. Körner, E. Maibach, A. Köhnen and K. Meerholz, Adv. Mater., 2013, 25, 4807-4813; (e) M. E. Gemayel, K. Börjesson, M. Herder, D. T. Duong, J. A. Hutchison, C. Ruzié, G. Schweicher, A. Salleo, Y. Geerts, S. Hecht, E. Orgiu and P. Samori, Nat. Commun., 2015, 6, 6330; $(f)$ T. Mosciatti, M. G. del Rosso, M. Herder, J. Frisch, N. Koch, S. Hecht, E. Orgiu and P. Samorì, Adv. Mater., 2016, 28, 6606-6611.

4 (a) S. Kobatake, S. Takami, H. Muto, T. Ishikawa and M. Irie, Nature, 2007, 466, 778-781; (b) M. Irie and M. Morimoto, Pure Appl. Chem., 2009, 81, 1655-1665; (c) M. Morimoto and M. Irie, J. Am. Chem. Soc., 2010, 132, 14172-14178; (d) F. Terao, M. Morimoto and M. Irie, Angew. Chem., Int. Ed., 2012, 51, 901-904; (e) D. Kitagawa, H. Nishi and S. Kobatake, Angew. Chem., Int. Ed., 2013, 52, 9320-9322.

5 (a) M. Irie, Chem. Rev., 2000, 100, 1685-1716; (b) H. BouasLaurent and H. Durr, Pure Appl. Chem., 2001, 73, 639-665; (c) A. J. Myles and N. R. Branda, Adv. Funct. Mater., 2002, 12, 167-173; (d) C.-C. Ko and V. W.-W. Yam, J. Mater. Chem., 2010, 20, 2063-2070; (e) J. Zhang, Q. Zou and H. Tian, Adv. Mater., 2013, 25, 378-399; (f) W. A. Velema, W. Szymanski and B. L. Feringa, J. Am. Chem. Soc., 2014, 136, 2178-2191; $(g)$ M. Irie, T. Fukaminato, K. Matsuda and S. Kobatake, Chem. Rev., 2014, 114, 12174-12277.

6 (a) G. M. Tsivgoulis and J.-M. Lehn, Angew. Chem., Int. Ed., 1995, 34, 1119-1122; (b) G. M. Tsivgoulis and J.-M. Lehn, Adv. Mater., 1997, 9, 627-630; (c) A. Fernandez-Acebes and J.-M. Lehn, Adv. Mater., 1998, 10, 1519-1522; (d) M. Irie, T. Fukaminato, T. Sasaki, N. Tamai and T. Kawai, Nature, 2002, 420, 759-760; (e) A. Peters and N. R. Branda, J. Am. Chem. Soc., 2002, 125, 3404-3405; (f) J. J. D. de Jong, L. N. Lucas, R. M. Kellogg, J. H. van Esch and B. L. Feringa, Science, 2004, 304, 278-281; $(g)$ T. J. Wigglesworth, D. Sud, T. B. Norsten, V. S. Lekhi and N. R. Branda, J. Am. Chem. Soc., 2005, 127, 7253-7255; (h) J. J. D. de Jong, T. D. Tiemersma-Wegman, J. H. van Esch and B. L. Feringa, J. Am. Chem. Soc., 2005, 127, 1380413805; ( $i$ ) K. Uno, H. Niikura, M. Morimoto, Y. Ishibashi, H. Miyasaka and M. Irie, J. Am. Chem. Soc., 2011, 133, 13558-13564; (j) D. Sud, T. B. Norsten and N. R. Branda, Angew. Chem., Int. Ed., 2005, 44, 2019-2021; $(k)$ L. Hou, X. Zhang, T. C. Pijper, W. R. Browne and B. L. Feringa, J. Am. Chem. Soc., 2014, 136, 910-913.

7 V. W.-W. Yam, C.-C. Ko and N. Zhu, J. Am. Chem. Soc., 2004, 126, 12734-12735.

8 (a) P. H.-M. Lee, C.-C. Ko, N. Zhu and V. W.-W. Yam, J. Am. Chem. Soc., 2007, 129, 6058-6059; (b) V. W.-W. Yam,
J. K.-W. Lee and N. Zhu, J. Am. Chem. Soc., 2009, 131, 912913.

9 (a) C.-T. Poon, W. H. Lam, H.-L. Wong and V. W.-W. Yam, J. Am. Chem. Soc., 2010, 132, 13992-13993; (b) C.-T. Poon, W. H. Lam and V. W.-W. Yam, J. Am. Chem. Soc., 2011, 133, 19622-19625; (c) J. C.-H. Chan, W. H. Lam, H.-L. Wong, N. Zhu, W.-T. Wong and V. W.-W. Yam, J. Am. Chem. Soc., 2011, 133, 12690-12705.

10 S. Kawai, T. Nakashima, K. Atsumi, T. Sakai, M. Harigai, Y. Imamoto, H. Kamikubo, M. Kataoka and T. Kawai, Chem. Mater., 2007, 19, 3479-3483.

11 (a) S. Fukumoto, T. Nakashima and T. Kawai, Angew. Chem., Int. Ed., 2011, 50, 1565-1568; (b) T. Nakashima, K. Tsuchie, R. Kanazawa, R. Li, S. Iijima, O. Galangau, H. Nakagawa, K. Mutoh, Y. Kobayashi, J. Abe and T. Kawai, J. Am. Chem. Soc., 2015, 137, 7023-7026.

12 (a) C.-C. Ko, W. H. Lam and V. W.-W. Yam, Chem. Commun., 2008, 5203-5205; (b) H.-L. Wong, C.-C. Ko, W. H. Lam, N. Zhu and V. W.-W. Yam, Chem.-Eur. J., 2009, 15, 1000510009.

13 (a) W. Zhu, Y. Yang, R. Métivier, Q. Zhang, R. Guillot, Y. Xie, H. Tian and K. Nakatani, Angew. Chem., Int. Ed., 2011, 50, 10986-10990; (b) W. Li, C. Jiao, X. Li, Y. Xie, K. Nakatani, H. Tian and W. Zhu, Angew. Chem., Int. Ed., 2014, 53, 4603-4607; (c) W. Li, X. Li, Y. Xie, Y. Wu, M. Li, X.-Y. Wu, W.-H. Zhu and H. Tian, Sci. Rep., 2015, 5, 9186; (d) J. Yoon and A. P. de Silva, Angew. Chem., Int. Ed., 2015, 54, 97549756; (e) X. Li, W. Li, H. Ågren, H. Tian and W. Zhu, Dyes Pigm., 2016, 125, 348-355.

14 J. C.-H. Chan, W. H. Lam and V. W.-W. Yam, J. Am. Chem. Soc., 2014, 136, 16994-16997.

15 (a) T. Baumgartner and R. Réau, Chem. Rev., 2006, 106, 46814727; (b) T. Baumgartner, Acc. Chem. Res., 2014, 47, 16131622.

16 (a) Y. Ren and T. Baumgartner, J. Am. Chem. Soc., 2011, 133, 1328-1340; (b) P.-A. Bouit, A. Escande, R. Szücs, D. Szieberth, C. Lescop, L. Nyulászi, M. Hissler and R. Réau, J. Am. Chem. Soc., 2012, 134, 6524-6527.

17 (a) O. Fadhel, M. Gras, N. Lemaitre, V. Deborde, M. Hissler, B. Geffroy and R. Réau, Adv. Mater., 2009, 21, 1261-1265; (b) C. Romero-Nieto, S. Durben, I. M. Koemos and T. Baumgartner, Adv. Funct. Mater., 2009, 19, 3625-3631; (c) K. H. Park, Y. J. Kim, G. B. Lee, T. K. An, C. E. Park, S.-K. Kwan and Y.-H. Kim, Adv. Funct. Mater., 2015, 25, 3991-3997.

18 The only phosphole-containing photochromic compounds reported are thiophene-fused dithienylethene derivatives with less impressive thermal stability and fatigue resistance( $a$ ) J. C.-H. Chan, W. H. Lam, H.-L. Wong, W.-T. Wong and V. W.-W. Yam, Angew. Chem., Int. Ed., 2013, 52, 11504-11508; (b) J. C.-H. Chan, W. H. Lam, H.-L. Wong, W.-T. Wong and V. W.-W. Yam, Chem.-Eur. J., 2015, 21, 6936-6948.

19 (a) Y. Unoh, K. Hirano, T. Satoh and M. Miura, Angew. Chem., Int. Ed., 2013, 52, 12975-12979; (b) Y.-R. Chen and W.-L. Duan, J. Am. Chem. Soc., 2013, 135, 16754-16757; (c) C. Hay, C. Fischmeister, M. Hissler, L. Toupet and R. Réau, 
Angew. Chem., Int. Ed., 2000, 39, 1812-1815; (d) P.-A. Bouit, A. Escande, R. Szücs, D. Szieberth, C. Lescop, L. Nyulászi, M. Hissler and R. Réau, J. Am. Chem. Soc., 2012, 134, 65246527; (e) Q. Xu, C.-Q. Zhao and L. B. Han, J. Am. Chem. Soc., 2008, 130, 12648-12655; (f) Y. Matano, A. Saito,
T. Fukushima, Y. Tokudome, F. Suzuki, D. Sakamaki, H. Kaji, A. Ito, K. Tanaka and H. Imahori, Angew. Chem., Int. Ed., 2011, 50, 8016-8020.

20 Y. Ren and T. Baumgartner, J. Am. Chem. Soc., 2011, 133, 1328-1340. 